\title{
Male Patients Benefit from Initial Exenatide Treatment: A Real-World Experience
}

Authors : Chen liang , Kuang jian, Pei jianhao, Chen hongmei, Chen zhong, Li zhongwen, Yang huazhang , Fu xiaoyin ,Wang long, Chen zhijiang, Linjinxin

Hospital: The First Division of Endocrinology, Guangdong General Hospital, Guangdong Academy of Medical Sciences, 106th of Zhongshan Er Road, Guangzhou 510080, China.

\begin{tabular}{|c|c|c|}
\hline OBJECTIVES & \multicolumn{2}{|r|}{ METHODS } \\
\hline $\begin{array}{l}\text { The purpose of this } \\
\text { study was to describe } \\
\text { the outcome after in- } \\
\text { itiation of exenatide } \\
\text { therapy and to de- } \\
\text { termine whether the } \\
\text { impact of adverse } \\
\text { drug reactions on } \\
\text { compliance was } \\
\text { affected by gender. }\end{array}$ & \multicolumn{2}{|c|}{$\begin{array}{l}\text { A retrospective study was performed of } 18 \text { dia- } \\
\text { betic patients ( } 8 \text { males) that were prescribed } \\
\text { exenatide between June } 2013 \text { and September } 2014 \text {. } \\
\text { Each included patient received exenatide for } \geq 1 \\
\text { month. Age, disease course, race, body mass index, } \\
\text { medical history, chronic complications asso- } \\
\text { ciated with diabetes, and the state of pretreatment } \\
\text { glycemic control were analyzed. Both } 1 \text { and } 4 \\
\text { weeks after treatment, data such as blood glucose, } \\
\text { blood lipids, and body weight were collected to de- } \\
\text { termine any adverse drug reactions and the impact } \\
\text { of gender on exenatide withdrawal. }\end{array}$} \\
\hline \multicolumn{2}{|c|}{ Tabie 1 Demograpnic and clinical characteristics of the study group } & Figure 1 ADR of Exenatide in male and females \\
\hline Characterisitis & 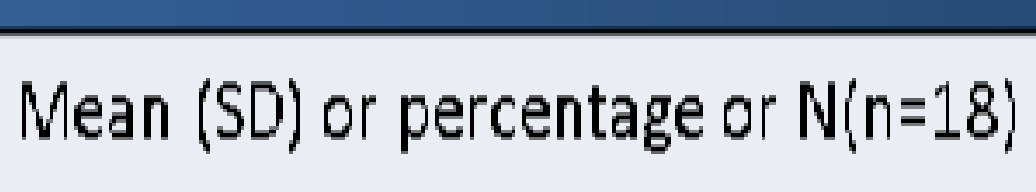 & ${ }^{14}$ \\
\hline 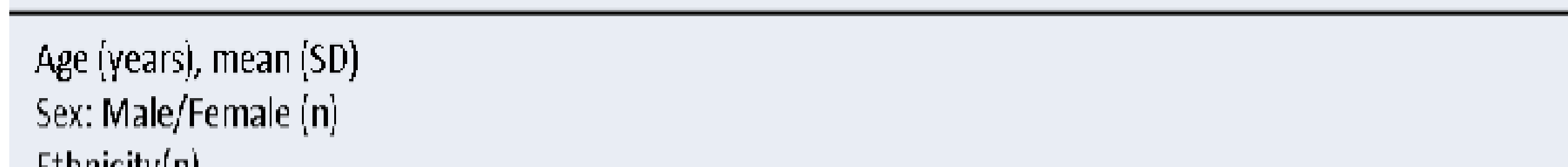 & 28.683) & \\
\hline 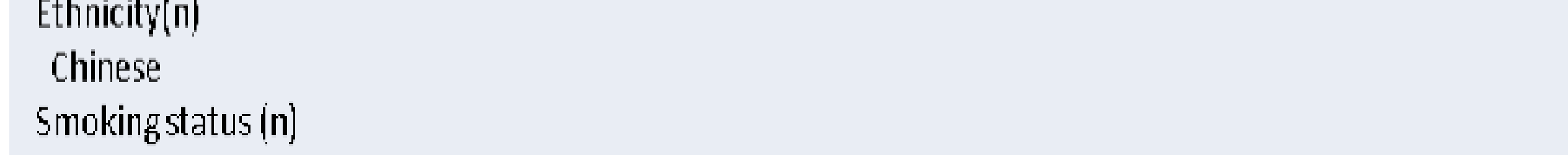 & 18 & 蜜 8 \\
\hline 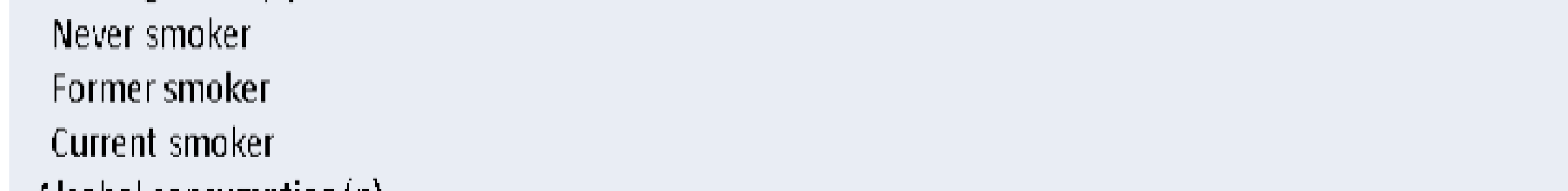 & $\begin{array}{l}15 \\
0^{15}\end{array}$ & $\begin{array}{ll}0^{2} \\
4\end{array}$ \\
\hline 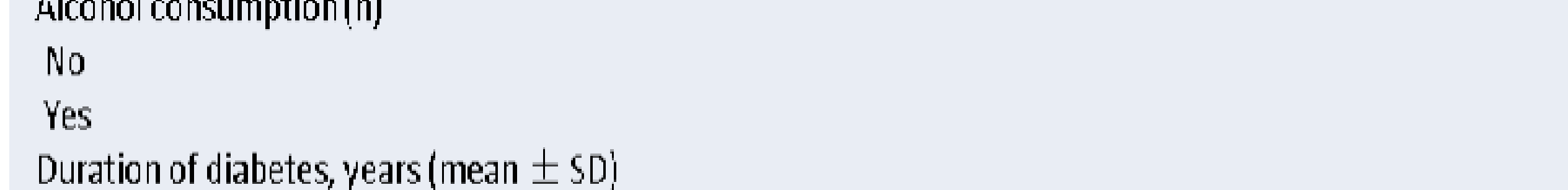 & $\begin{array}{l}18 \\
0.3544 \\
0.354\end{array}$ & $\begin{array}{l}2 \\
0\end{array}$ \\
\hline 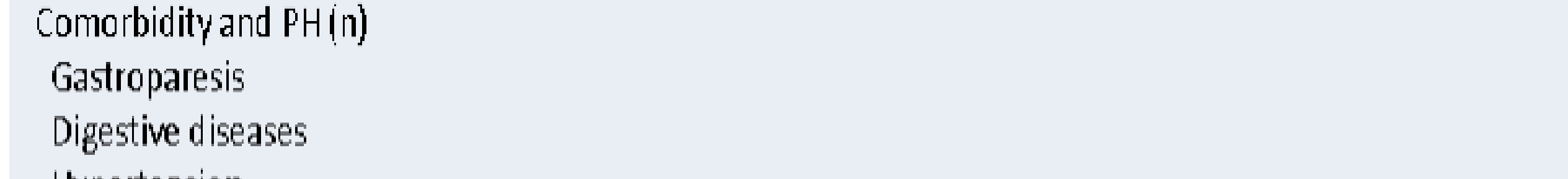 & $\frac{0}{2}$ & time \\
\hline 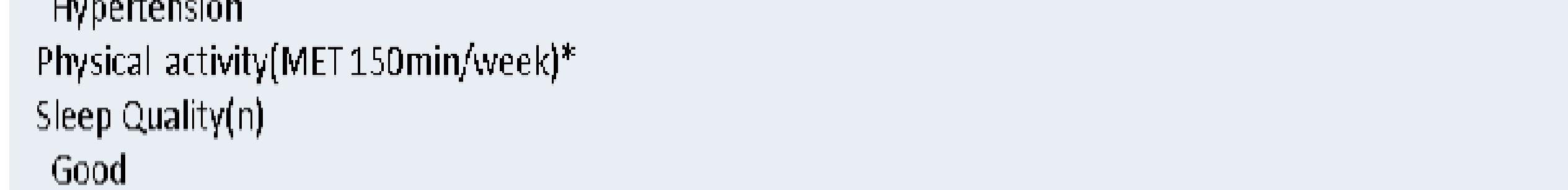 & & \\
\hline 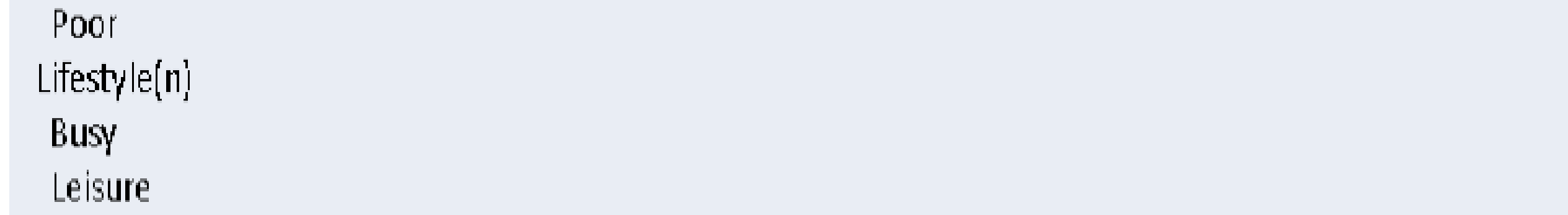 & $?$ & Male \\
\hline 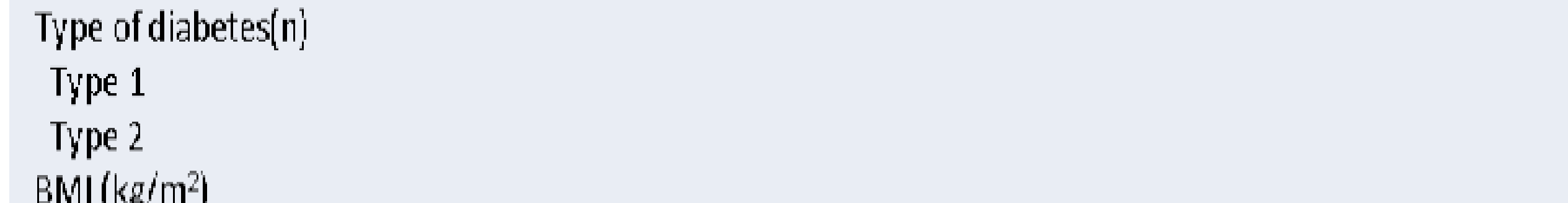 & $\underbrace{0}_{18}$ & U \\
\hline 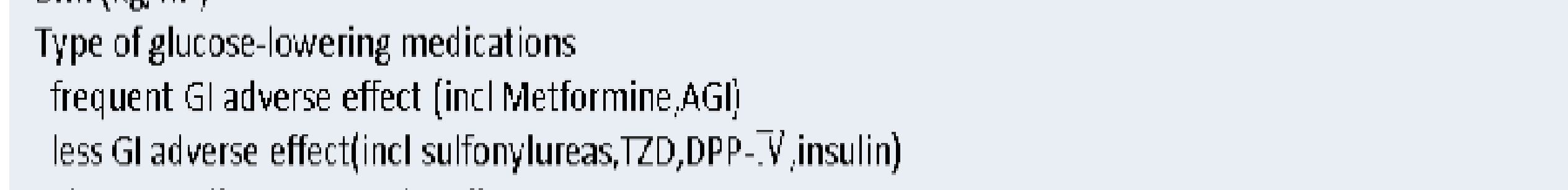 & 16 & आூת \\
\hline 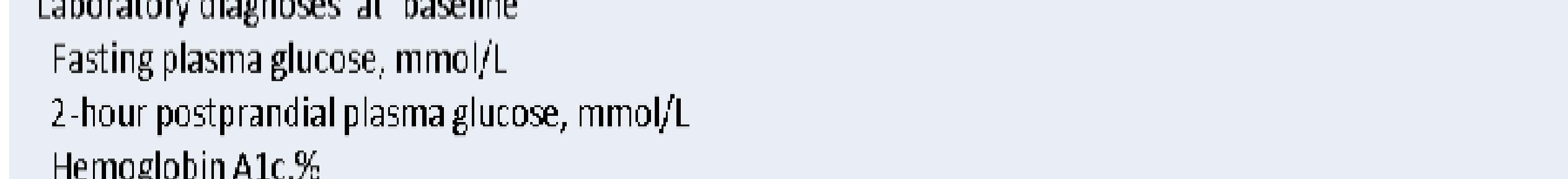 & 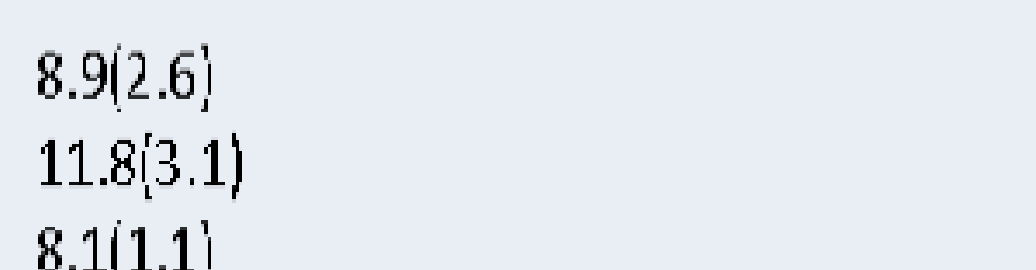 & \\
\hline & & \\
\hline
\end{tabular}

\section{RESULTS}

The incidence of adverse drug reaction was significantly higher in female than male patients following exenatide treatment $(P$ $<.05)$. Although there was no significant difference between the male and female group 1 week, adverse drug reactions continued longer in females and the incidence of adverse drug reaction was significantly higher in female patients 4 weeks after initiating treatment $(P<.01)$. As a result, four female patients stopped taking the medication, whereas only one male patient stopped taking the medication because the patient was unaccustomed to the drug injection process. The efficacy of exenatide was similar between the two groups at both 1 and 4 weeks.

\section{CONCLUSIONS}

Exenatide, a glucagon-like peptide-l agonist often causes relatively significant gastrointestinal reactions during its initial application. Gender difference in adverse drug reactions may be due to the impact of this drug on the feeding center in the central nervous system. 